\title{
Toxic megacolon and human Cytomegalovirus in a series of severe ulcerative colitis patients
}

\author{
Valeria Criscuoli ${ }^{\mathrm{a}}$, Maria Rosa Rizzuto ${ }^{\mathrm{b}}$, Elena Gallo ${ }^{\mathrm{b}}$, Ambrogio Orlando $^{\mathrm{a}}$, \\ Mario Cottone ${ }^{a, *}$ \\ ${ }^{a}$ Biomedical Department of Internal and Specialist Medicine (DIBIMIS), Division of Medicine, Villa Sofia-V. Cervello Hospital, Palermo University, \\ Palermo, Italy \\ ${ }^{\mathrm{b}}$ Institute of Pathology “Villa Sofia-V. Cervello Hospital”, Palermo University, Palermo, Italy
}

\section{A R T I C L E I N F O}

\section{Article history:}

Received 3 March 2015

Received in revised form 10 March 2015

Accepted 12 March 2015

\section{Keywords:}

Cytomegalovirus

Ulcerative colitis

Megacolon

\begin{abstract}
A B S T R A C T
Background: Human Cytomegalovirus (HCMV) infection has been reported to be a cause of refractory ulcerative colitis (UC). Toxic megacolon (TM) is a rare but severe complication of an acute attack of UC. Objectives: Aim of this study is to evaluate in a case-control study the association between HCMV and TM.

Study design: All patients who were admitted at Medicine Department of V. Cervello Hospital in Palermo (tertiary referral center) for a severe UC flare-up complicated by the onset of TM (diameter of the transverse colon $>6 \mathrm{~cm}$ ) between January 1990 and November 2011 were identified through the electronic database. A total of 24 consecutive patients ( 16 male/ 8 female) with TM were identified. Each case of TM were individually matched by sex, age, extent of the underlying disease to 24 severe UC controls who did not develop TM. A further non matched control population of 48 severe UC was included.

Haematoxilin and eosin stain, immunohistochemical procedure and nested polymerase chain reaction were performed to detect HCMV genes and proteins on rectal biopsies or surgical specimens. Pp65 antigenemia was performed in order to diagnose any possible systemic infection. HCMV frequency was compared between patients with and without TM during follow-up, using Fisher's Exact test.

Results and conclusions: HCMV was detected in histological specimens of 11 patients (46\%) with TM compared to $2(9 \%)$ severe UC matched controls $(P=0.0078)$ and $7(14 \%)$ unmatched controls $(p=0,003)$. In severe colitis the presence of HCMV is more frequently associated with TM.
\end{abstract}

(C) 2015 Elsevier B.V. All rights reserved.

\section{Background}

TM is a well recognized, potentially fatal complication of UC and denotes a clinical syndrome of systemic toxicity accompanied by radiographic evidence of colonic dilatation. First described in 1950, TM is a potentially lethal complication of inflammatory bowel disease (IBD) or infectious colitis, characterized by total or segmental non-obstructive colonic dilatation of at least $6 \mathrm{~cm}$ associated with systemic toxicity. Criteria for the diagnosis of TM in adults were proposed by Jalan et al. [1].

Among infective cause Clostridium difficile [3], Salmonella, Shigella, Yersinia, Campylobacter and, above all in AIDS patients, Cryptosporidium, Entameba and HCMV were recognized.
A prospective study evaluated the prevalence rate of HCMV infection among a population of consecutive IBD patients with severe acute colitis, as well as the prevalence of this infection among the subgroups of steroid refractory patients. The prevalence of HCMV infection was $21 \%$ ( 9 out of 42 patients) [2]. The prevalence rate of HCMV infection in the steroid-refractory group was 33\% (4 out of 12 patients) which approximate the previous estimate in a previous series [3].

In one series, evidence of HCMV infection was found in the resected colon of 6 of 46 patients with UC. Five of these six patients but only 2 of the 40 patients without HCMV infection had TM [4]. Further cases reports described the association between HCMV and TM [5-7] but it is not clear if HCMV is more frequent in TM than in severe colitis.

\footnotetext{
* Corresponding author. Tel.: +39 3385358045.

E-mail address: cottonedickens@gmail.com (M. Cottone).
} 
Table 1

Patient and disease characteristics of TM patients and control group.

\begin{tabular}{llll}
\hline & TM patient & Control matched & $\begin{array}{l}\text { Controls } \\
\text { Not matched }\end{array}$ \\
\hline $\begin{array}{l}\text { No. of patients (M/F) } \\
\text { Age at admission }\end{array}$ & $\begin{array}{l}24(16 / 8) \\
45,5(15-70)\end{array}$ & $\begin{array}{l}24(16 / 18) \\
37,4(18-76)\end{array}$ & $\begin{array}{l}48(31 / 17) \\
39(18-71)\end{array}$ \\
$\begin{array}{l}\text { Disease extent } \\
\text { \# Pancolitis N. (\%) }\end{array}$ & $15(62.5 \%)$ & $14(58 \%)$ & $20(41 \%)$ \\
\# Left-sided N. (\%) & $9(37.5 \%)$ & $10(42 \%)$ & $28(59 \%)$ \\
$\begin{array}{l}\text { Steroid-dependance } \\
\text { Previous therapy }\end{array}$ & $11(46 \%)$ & $16(66 \%)$ & $15(31 \%)$ \\
$\begin{array}{l}\text { Mesalamine } \\
\text { Azathioprine }\end{array}$ & $24(100 \%)$ & $24(100 \%)$ & $36(100 \%)$ \\
\hline
\end{tabular}

\section{Objectives}

Aim of this study was to retrospectively assess the frequency of HCMV infection in a consecutive series of severe UC complicated by TM compared to a control group.

\section{Study design}

This was a retrospective study conducted in a single tertiary referral center.

In our unit since 1975, all the patients admitted for severe ulcerative colitis were evaluated clinically with the Truelove and Witts criteria [8] and with a plain X-ray of the abdomen to evaluate the diameter of the transverse colon. Patient was diagnosed to have megacolon if the diameter of the transverse colon was $>6 \mathrm{~cm}$. Patients during admission repeated plain X-ray of abdomen in relation to the clinical course.

Health records from 1990 to 2011 were electronically searched through a database for patients with the diagnosis of " megacolon"; exclusion criteria were infectious or ischemic colitis, Hirschsprung disease (HD) and the diagnosis of TM without a clear diagnosis of IBD. Each case of TM were individually matched by sex, age, extent of the underlying disease, year of onset of illness, to one severe UC controls who during the clinical course did not develop TM. A further control non matched population of 48 severe UC was identified from a cohort followed up from 2000 to 2004 in which patients matched with TM were excluded.

A total of 24 consecutive patients with TM (16 male/8 female; median age at diagnosis 45, 5 years) were identified. The study methodology was as follows: from 1990 to 1998 patients hospitalized for severe colitis underwent proctoscopy with rectal biopsy without air insufflations in those who developed steroid resistance after 5 days of conventional therapy. In case of megacolon proctoscopy was performed at diagnosis of this complication. From 1998 to 2011, patients underwent proctoscopy with rectal biopsy at the ward admission without waiting for the response to steroid therapy. Up to 1998 were identified a first series of 11 patients, and from 1999 to 2011 were identified a second series of 13 patients. Basic characteristics, medication and disease history are listed in Table 1.

Abdominal radiographs at the time of diagnosis with TM and subsequent radiographs during that admission, were compared with radiograph of the age-matched UC-controls and with unmatched controls.

\subsection{Laboratory techniques}

Surgical specimens or rectal biopsies were evaluated by a dedicate pathologist in order to identify the presence of HCMV by performing:
Table 2

Clinical characteristics and outcomes of patients with TM and HCMV+

\begin{tabular}{rlllll}
\hline & Age/sex & Relapse/onset & $\begin{array}{l}\text { Duration of } \\
\text { disease (year) }\end{array}$ & Extent of disease & Outcome \\
\hline 1 & $\mathrm{~F} / 53$ & $\mathrm{R}$ & 31 & $\mathrm{P}$ & $\mathrm{C}$ \\
2 & $\mathrm{M} / 48$ & $\mathrm{R}$ & 16 & $\mathrm{~T}$ & $\mathrm{C}$ \\
3 & $\mathrm{M} / 63$ & $\mathrm{O}$ & 0 & $\mathrm{P}$ & $\mathrm{C} / \mathrm{E}$ \\
4 & $\mathrm{M} / 45$ & $\mathrm{O}$ & 0 & $\mathrm{P}$ & $\mathrm{C} / \mathrm{E}$ \\
5 & $\mathrm{~F} / 75$ & $\mathrm{R}$ & 20 & $\mathrm{P}$ & $\mathrm{E}$ \\
6 & $\mathrm{~F} / 70$ & $\mathrm{R}$ & 11 & $\mathrm{~T}$ & $\mathrm{~A}$ \\
7 & $\mathrm{M} / 46$ & $\mathrm{R}$ & 16 & $\mathrm{~L}$ & $\mathrm{C}$ \\
8 & $\mathrm{M} / 17$ & $\mathrm{R}$ & 2 & $\mathrm{P}$ & $\mathrm{C}$ \\
9 & $\mathrm{M} / 22$ & $\mathrm{R}$ & 8 & $\mathrm{P}$ & $\mathrm{C}$ \\
10 & $\mathrm{M} / 55$ & $\mathrm{R}$ & 11 & $\mathrm{P}$ & $\mathrm{C}$ \\
11 & $\mathrm{M} / 32$ & $\mathrm{R}$ & 2 & $\mathrm{P}$ & $\mathrm{C}$ \\
\hline
\end{tabular}

$\# \mathrm{P}=$ pancolitis, $\mathrm{T}=$ transverse, $\mathrm{L}=$ left colitis, $\S \mathrm{C}=$ colectomy, $\mathrm{A}=$ antiviral therapy, $\mathrm{E}=$ exitus

- Light microscopy with Haematoxilin and Eosin (H\&E) stain in order to document the microscopic disease activity and allow the detection of cytomegalic cells, markers of infected viral cells.

- Immunohistochemical (ICH) procedure for HCMV performed on a paraffin-embedded section with monoclonal mouse antibodies anti-Human CMV (clone BM204) and conjugated to a peroxidaselabeled amino acid polymer by peroxidase-antiperoxidase (PAP) method in order to detect viral proteins. Nuclear or cytoplasmic antigen was identified by the typical brown reaction product of the PAP method.

- Nested polymerase chain reaction $\left({ }_{n} \mathrm{PCR}\right)$ by using two pairs of primers annealed to the $\mathrm{gB}$ region of HCMV. Primers used for the first-round product and second-round PCRs are as follows $\left(5^{\prime}-3^{\prime}\right)$ : first-round primer 1, GAGGACAACGAAATCCTGTTGGGCA; firstround primer 2, GTCGACGGTGGAGATACTGCTGAGG; secondround primer 3, ACCACCGCACTGsAGGAATGTCAG; and secondround primer 4, TCAATCATGCGTTTGAAGAGGTA, to obtain a HCMV fragment of $100 \mathrm{bp}$.

The PCR amplification products were run on $2 \%$ agarose gel and stained with ethidium bromide and visualized under ultraviolet light.

On peripheral blood was also performed:

- Pp65 antigenemia consist of the detection of the viral pp65 tegument protein by immunofluorescence in polymorphonuclear neutrophils (PNML), previously recovered from a blood buffycoat. The result was expressed as the number of positive cells per 200.000 PNML.

\subsection{Statistical analysis}

Presence of HCMV were compared between patients with TM and 2 controls population, using chi-square statistics, Fisher's Exact test. Data were analyzed using the software package SPSS 15150 (SPSS Inc., Chicago, IL, USA).

\section{Results}

Among the 24 patients identified in the series, HCMV was detected in histological specimens of 11 patients (46\%) (Table 2) with severe UC complicated with TM, compared to 2 (9\%) matched controls $(P=0.0078)$ and $7(14 \%)(p=0,003)$ unmatched controls.

Among the TM HCMV + patients, the virus was identified in rectal biopsies in seven and in surgical specimen in four. The rate of steroid-resistance in patients with TM was 45\% (5/11) among the first series and 53\% (7/13) among the second series. Steroid resistance was $21 \%$ among matched (5/24) and 20\% (10/48) among un matched controls. 
Table 3

Comparison between the various diagnostic techniques.

\begin{tabular}{lcll}
\hline & Cases & Matched Controls & Unmatched \\
\hline HCMV-DNA+ (qualitative) & 11 & 2 & 7 \\
H\&O stain & 7 & 2 & 7 \\
ICH & 7 & 2 & 7 \\
Pp65 antigen & 8 & 2 & 0 \\
\hline
\end{tabular}

HCMV was identified with H\&E stain in 7 and with PCR in 11 patents with TM; among the matched control population HCMV was identified with H\&E stain and with PCR in 2 patients and among unmatched controls in 7 patients, respectively (Table 3 ). Systemic infection was identified in 8 patients with megacolon, in 2 patients among matched controls. No systemic infection was observed among unmatched controls.

In the TM group, 20 of $24(83 \%)$ patients underwent colectomy during the hospitalization, compared with 4 of 24 (18\%) matched controls $(P=0.0001)$ and $0 / 36$ among the unmatched controls. Among 11 TM HCMV positive patients 9 were operated on compared to 11 TM HCMV negative patients, showing a not statistically significant result. Among the TM patients HCMV+, 3 patients died during the hospitalization due to the worsening of clinical conditions.

Colectomy was performed in the control patients due to failure of intravenous corticosteroid therapy, and in one case due to failure of rescue therapy as Infliximab. All patients with HCMV except one were treated with anti-viral drugs. Among MT patients with HCMV, only 1 patients responded (treated with Vanganciclovir [9]). Among the 2 control groups, 7 patients with HMCV were treated with Ganciclovir, one with Foscarnet and one was not treated. Only one patient did not respond and was operated on.

\section{Discussion}

This paper shows that there was a significant higher incidence of HCMV infection in the colon of patients with UC complicated by $\mathrm{TM}$, suggesting a possible role of this viral infection in precipitating this condition.

The results are hampered from the fact that the search for HCMV was more extensive in those operated on but if we exclude those in which the virus was detected in the surgical specimens the difference was still significant. Furthermore, the retrospective nature of the study may weakens the conclusions; TM is a rare condition and prospective studies are difficult to set up and require the participation of many center for a long period of time. In order to give strength to the results, we evaluated 2 types of controls (matched and unmatched) because it was difficult to find matched controls.

In the literature, many single cases [10-12] and 3 small series of TM [13-14] associated to HCMV are reported. Cooper et al. [4] detected HCMV infection in the resected colon of 6 of 46 patients with UC. Five of these six patients but only 2 of the 40 patients without HCMV infection had TM, whereas Eyre-Brook et al. [15] and Barahona-Garrido et al. [16] did not show evidence for HCMV in 3 patients with TM and a low prevalence in 47 patients operated on for colectomy, respectively. The reason why HCMV is more frequent in TM is quite uncertain.

The only possible risk factor for superimposed HCMV infection is previous immunosuppression [17], but in our series patients who developed TM had a lower rate of immunosuppressive therapy before admission.

One could make the hypothesis of a role of the virus on the ganglionic cells like in HD where congenital HCMV infection is correlated with development of the disease. Multiple strains of virus circulate both within the population and within an individual, and evidence exists for inter-strain recombination [18-19]. There are no data on the genetic variants of HCMV in IBD.

It is not clear if the use of antiviral therapy determines a regression of TM. We reported a case [9] which show a response to oral Valgangiclovir with regression of colonic dilatation suggesting a possible role of this therapy, but the single case is not sufficient to draw any conclusion. The risk and benefits of HCMV anti-viral therapy need to be considered before decisions and are taken according to clinical conditions and viral load detected by molecular diagnostic techniques such as ${ }_{n}$ PCR. HCMV anti-viral drugs have the potential for serious side effects, including bone marrow suppression, pulmonary and neurological dysfunction; so robust evidence of benefit is needed.

$\mathrm{TM}$ is a rapid progressive complication and it is difficult to state that antiviral therapy is able in few days to reverse this condition.

Our paper does not show an increased risk of surgery for those with HCMV indicating that the possible treatment of the virus does not seem to be relevant in a brief term period.

\section{Competing interest}

There was conflict of interest from all authors.

\section{Funding}

No funding was received for this study.

\section{Ethical approval}

Being a retrospective study no ethical approval was necessary.

\section{References}

[1] K.N. Jalan, W. Sircus, W.I. Card, et al., An experience of ulcerative colitis: toxic dilation in 55 cases, Gastroenterology 57 (1969) 68-82.

[2] V. Criscuoli, A. Casà, G. Orlando, G. Pecoraro, L. Oliva, M. Traina, A. Rizzo, M. Cottone, Severe acute colitis associated with CMV: a prevalence study, Dig. Liver Dis. 36 (2004) 818-820.

[3] M. Cottone, G. Pietrosi, G. Martorana, A. Casa, G. Pecoraro, Oliva 1, A. Orlando M. Rosselli, A. Rizzo, L. Pagliaro, Prevalence of cytomegalovirus infection in severe refractory ulcerative and Crohn's colitis, Am. J. Gastroenterol. 96 (2001) 773-775.

[4] H.S. Cooper, E.C. Raffensper, L. Jonas, et al., Cytomegalovirus inclusions in patients with ulcerative colitis and toxic dilatation requiring colonic resection Cytomegalovirus inclusions in patients with ulcerative colitis and toxic dilatation requiring colonic resection, Gastroenterology 72 (1977) 1253-1256.

[5] K. Inoue, N. Wakabayashi, K. Fukumoto, S. Yamada, N. Bito, N. Yoshida, K. Katada, K. Uchiyama, T. Ishikawa, O. Handa, T. Takagi, H. Konishi, N. Yagi, S. Kokura, A. KishimotoM. Yanagisawa, Y. Naito, Toxic megacolon associated with cytomegalovirus infection in a patient with steroid-naïve ulcerative colitis, Intern. Med. 51 (19) (2012) 2739-2743.

[6] Y.H. Lin, C.J. Yeh, M.C. Chen, et al., Recurrent cytomegalovirus colitis with megacolon in an immunocompetent elderly man, J. Med. Virol. 82 (4) (2010) 638-641.

[7] J.J. Orloff, R. Saito, S. Lasky, H. Dave, Toxic megacolon in cytomegalovirus, Am. J. Gastroenterol. 84 (7) (1989) 794-797.

[8] S.C. Truelove, L.J. Witts, Cortisone in ulcerative colitis final report on an therapeutic trial, Br. Med. J. 29 (2) (1955) 1041-1048 (4947).

[9] V. Criscuoli, S. Plano, E. Aragona, M. Cottone, Oral valganciclovir for colonic dilatation in ulcerative colitis associated with human cytomegalovirus infection, Inflamm. Bowel Dis. 16 (5) (2010) 727-728.

[10] H. Kotanagi, T. Fukuoka, Y. Shibata, et al., A case of toxic megacolon in ulcerative colitis associated with cytomegalovirus infection, J. Gastroenterol. 29 (4) (1994) 501-505.

[11] S. Laurent, C. Reenaers, B. Detroz, et al., A patient who survived total colonic ulcerative colitis superinfected by cytomegalovirus complicated by toxic megacolon and disseminated intravascular coagulation, Acta Gastroenterol. Belg. 68 (2) (2005) 276-279.

[12] Y. Shimada, T. Iiai, H. Okamoto, et al., Toxic megacolon associated with cytomegalovirus infection in ulcerative colitis, Gastroenterology 38 (2003) 1107-1108.

[13] M.B. Grieco, D.L. Bordan, A.C. Geiss, et al., Toxic megacolon complicating Crohn's colitis, Ann. Surg. 191 (1980) 75-80.

[14] A.J. Greenstein, D.B. Sachar, A. Gibas, et al., Outcome of toxic dilatation in ulcerative and Crohn's colitis, J. Clin. Gastroenterol. 7 (1985) 137-143. 
[15] I.A. Eyre-Brook, S. Dundas, Incidence and clinical significance of colonic cytomegalovirus infection in idiopathic inflammatory bowel disease requiring colectomy, Gut 27 (December (12)) (1986) 1419-1425.

[16] J. Barahona-Garrido, B. Martínez-Benítez, E. Espinosa-Cárdenas, et al., Cytomegalovirus infection in patients who required colectomy for toxic megacolon or severe steroid-refractory ulcerative colitis, Dig. Dis. Sci. 55 (3) (2010) 867-868.

[17] M. Boeckh, W.G. Nichols, Immunosuppressive effects of beta-herpesviruses, Herpes 10 (2003) 12-16.
[18] S. Pignatelli, P. Dal Monte, G. Rossini, et al., Genetic polymorphism among human cytomegalovirus wild-type strains, Rev. Med. Virol. 14 (2004) 383-410.

[19] K. Tanaka, K. Numazaki, H. Tsutsumi, Human cytomegalovirus genetic variability in strains isolated from Japanese children during 1983-2003, J. Med. Virol. 76 (2005) 356-360. 